Biosimilars for Healthcare Professionals

For personal use only. Not to be reproduced without permission of the publisher (editorial@gabi-journal.net).

\title{
Is Australia positioned to take advantage of biosimilars?
}

\author{
David Lim, DPH
}

Australia currently has a small generic and biosimilar medicine industry despite having a good track record in biomedical research and a sound reputation in producing high quality but small volume biological pharmaceuticals. In recent times, Australia has made incremental changes to its regulation of biosimilars - in patent registration, in the use of commercial confidential information, and in remuneration. These improvements, together with Australia's geographical proximity and strong trade relationship with the Asian biocluster, have positioned Australia to take advantage of potential public cost savings from the increased use of biosimilars.

Keywords: Australia, biosimilars, confidential information, patent, regulation, remuneration

\section{Introduction}

The cost of providing health care has increased significantly worldwide [1]. Efficient and effective cost-containment measures are desired [2]. The use of generic pharmaceuticals is of interest to health economists because generics are usually cheaper than originators, hence, they contribute to a sustainable health system [3]. Similarly, cost savings are expected from the increased use of biosimilars [4].

Despite the fact that biosimilars are relatively new - the MeSH term 'biosimilar pharmaceuticals' was only introduced in 2012 - the biosimilars market is potentially the single fastest growing pharmaceutical sector, with an estimated US\$67 billion in global sales by 2020 [5]. This has stimulated the emergence of non-conventional pharmaceutical investors such as Fujifilm and Samsung, as well as countries such as Brazil, China, India, Mexico, South Korea, Russia and Turkey, who view biosimilars as a key macroeconomic driver of growth [5].

Australia is a relatively small and new pharmaceutical market with a good reputation in producing high quality but small volume biological pharmaceuticals [6, 7]. At a recent national medicines conference, the Australian regulator - Therapeutic Goods Administration (TGA) - indicated that Australia was ready for biosimilars. Specifically, TGA sees its role in 'posing as few barriers as possible to the registration of biosimilars, while simultaneously assuring the quality, safety and efficacy of those biosimilars both before and after registration' [8]. The focus of this article is to appraise TGA's proposed role, with a focus on whether Australia is positioned to take advantage of biosimilars. Specifically, the issues of biosimilars in relation to the Australian patent scheme, the use of commercial confidential information by TGA, and remuneration under the national Pharmaceutical Benefits Scheme (PBS) are discussed.

\section{Preregistration: patent}

The critical question concerning the regulation of biosimilars is whether the current Australian patent system impedes the entry of biosimilars into the marketplace.

Prior to registration of biosimilars with regulators and eventual marketing of the product, a key step in the process is the application for patent protection. The Australian administrative agency for intellectual property - IP Australia - recently completed a review of Australia's pharmaceutical patent system. The panel of experts considered patentability of biosimilars and acknowledged that biosimilars are not considered to be bioequivalent to a reference biological product. This is due to the highly complex nature of biological medicinal products ... the clinical performance of biologic[al]s is often highly dependent on the methods of manufacturing and purification. Even minor differences in the environment or manufacturing process can compromise biological activity and safety for some biologic[al] drugs' [9]. The Panel further stated that there is a need for an integrated approach to the regulation of pharmaceuticals beyond patent issues [9]. The Panel felt that 'the patent landscape for biologic[al]s is no more complex than that for small-molecule drugs', and did not warrant specific patent protection, such as increased length of confidential data protection or extended patent terms.

Innovators often file for separate patent protection for their upstream manufacturing process and their downstream end product at the same time. For biosimilars, the upstream-downstream nexus is arguably more relevant than for small molecule generics, especially with respect to safety and efficacy. For example, when the biosimilar epoetin alfa, Eprex was blamed for increased immunogenicity and development of pure red cell aplasia, two hypothetical causes were suggested: (i) leachates from uncoated rubber stoppers, and (ii) the change from human serum albumin to polysorbate- 80 as a stabilizer [10, 11]. Any differences in the upstream production of biosimilars can result in significant differences in the biological characteristics of the downstream end product.

It is generally accepted that the aim of the Australian patent system is primarily economic: an exchange of exclusive rights in return for innovation [12]. If indeed the principal objective of the Australian patent system is to incentivize innovation, one must rightly question whether the consequence of the innovator's attempt to patent and protect various modes of upstream manufacturing as well as the downstream end product does, in fact, stimulate innovation.

Author: David Lim, DPH, Lecturer, School of Clinical Sciences, Queensland University of Technology; Member, Institute of Health and Biomedical Innovation - Health Determinants and Health Services Theme, Queensland University of Technology, GPO Box 2434, Brisbane, Queensland, AU-4001, Australia

Submitted: 24 October 2014; Revised: 17 November 2014; Accepted: 20 November 2014; Published online first: 3 December 2014 
Australia recently enacted the Intellectual Property Laws Amendment (Raising the Bar) Act 2012 aiming to address the issue of the 'patent thicket'. The amendment came into effect in April 2013. Section 7 of the Patent Act 1990 was amended with respect to an element of the legal test that decides whether the subject of a patent application is 'inventive', and hence can be afforded patent protection. The amended section relates to the common general knowledge/prior art base, which a skilled addressee may consider when approving the patent application. The prior art base is no longer restricted to information extent in Australia. Furthermore, sections 18 and $7 \mathrm{~A}$ require that a patent needs to be of particular benefit to the public as disclosed in its current form, as opposed to whether it could prove useful at some future date after further research. Section 40(2)(a) further demands that the disclosure of the invention be clear enough, complete enough and contain the best method known to the patent applicant for the invention to be recreated by a person skilled in the relevant art. The effect of amended section 40(3) imposes on the patent applicant the duty to fairly base the description of each of its claims and mandates that the scope of the claims be not broader than is justified by the extent of the description. Section 199C further provides for certain types of non-commercial experimental activities to be undertaken without infringing on the innovator's patent rights. These include determining the properties of the invention, the scope of the patent claim, and the validity of the claim; as well as improving or modifying the invention. Collectively, the Raising the Bar amendments aim to restrict the scope of claims upon which the innovator can fairly base its invention thereby narrowing the scope of the patent and making it easier for a biosimilar sponsor to seek a patent for its product. The amendments may also have the effect of preventing 'evergreening' one's pharmaceutical product, once the patent has been granted.

\section{Registration: confidential information}

For a pharmaceutical product to be supplied in Australia, a sponsor must apply to TGA for its product to be listed in the Australian Register of Therapeutic Goods. During the assessment process, detailed product information, such as quality, safety and efficacy, and manufacturing information, must be submitted to TGA.

The European Medicines Agency (EMA) has led the regulation of biosimilars since 2003 . The regulatory process has been inclusive of both the pharmaceutical industry and the regulators through the development of concept papers, followed by draft guidelines. Clinical, non-clinical and product class guidelines are publicly available. Consequently, several countries have looked to EMA regulations for guidance. Specifically, TGA has opted to adopt the EMA guidelines in the regulation of biosimilars in Australia.

With respect to the naming of pharmaceutical products, TGA dictates that the name of a biosimilar is to be made up of: (i) the reference product's Australian Biologic Name, and (ii) a biosimilar identifier, consisting of the prefix $\operatorname{sim}(\mathrm{a})$ - and a three-letter code issued by the World Health Organization's (WHO) International Nonproprietary Name (INN) Committee. The three-letter code will eventually be harmonized to the four-letter code. The biosimilar sponsor will need to first apply to the WHO's INN Committee for a biosimilar four-letter code; then to the Australian Biologic Name Committee for the use of the INN three-letter code in the biosimilar identifier; and finally to request for this identifier to be added to the list of Australian Approved Names. If there are detectable quality differences in the biosimilar as compared with the innovator product, the biosimilar sponsor will also need a different Australian Biologic Name.

To evaluate the quality assurance of the manufacturing of biosimilars, knowledge of analytical methods, in-house standards, specifics of the production process, historical development process, validation and full characterization data are needed. However, these are deemed proprietary information and little is available in the public domain. A systematic review of research outcomes and pharmaceutical sponsorship found that research funded by the pharmaceutical industry was less likely than publicly-funded research to be published; and if published, more likely be in favour of the sponsor (OR 4.05, 2.98-5.51) [13]. There have been allegations that pharmaceutical companies have selectively published favourable findings of selffunded research, which bolster one's apparent success, and that unfavourable findings were not published. As information about the upstream process and methods of manufacturing are critical to the downstream biosimilar products, the handling of confidential information takes on extra importance.

Unlike the US's 12-year marketing exclusivity period for the innovator [14], Australia's data exclusivity is currently five years pursuant to section 25A of the Therapeutic Goods Act 1989. Within this time, TGA cannot without the permission of the innovator use the initial data submitted to assess an application for registration from a biosimilar sponsor. The data exclusivity provision does not, however, prevent a biosimilar manufacturer from conducting its own research and submitting its own dossier for listing by TGA within this data protection period.

Recently, TGA conducted a review of its policy on disclosure of commercially confidential information under section 61 of the Act. The review concluded that it is lawful for TGA to release confidential information to other national regulators (such as for the listing on the PBS) and international agencies [15]. This affirmation is of relevance to biosimilars especially given the global nature of trade and citizen movement, which warrants international collaboration in the regulation of quality, safety and efficacy of pharmaceuticals of all types. Specifically, the Australian Government signed a treaty with New Zealand that established a central agency (Australia New Zealand Therapeutic Products Agency) for the regulation of therapeutic goods in both countries; and, more recently, TGA has agreed to participate in the European Decentralised Procedure for the evaluation of generics [16]. There are similar moves for Europe, Japan and the US for harmonized evaluation $[17,18]$.

\section{Tracking immunogenicity}

It is not possible to predict the immunogenic potential of a biosimilar from its molecular structure or even from the results of preclinical and animal trials. In addition, the antibody response induced by a biosimilar may have a different character and clinical consequence compared with that of the innovator. A large and longer duration cohort study may be required to study safety and efficacy of a biosimilar. Such a pharmacovigilance study is expensive to conduct due to the duration of the study and the number of participants required. With a biosimilar, 
post-marketing pharmacovigilance may be the only means of conducting such an assessment. Sharing of information among national and international regulators may be a solution.

With biosimilars, such as filgrastim (rbe*) (Tevagrastim sponsored by Aspen Pharmacare Pty Ltd, Nivestim by Hospira Pty Ltd, Zarzio by Sandoz Pty Ltd, and Neupogen by Amgen Australia), batch-to-batch variation is to be expected. When there is only a single brand on the market, any adverse effect such as immunogenicity may be tracked to the innovator product if the Australian healthcare practitioner reports the adverse effect to the Advisory Committee on the Safety of Medicines. However, not all Australian community pharmacies currently provide batch tracking [19]. This poses a logistical issue in post-marketing pharmacovigilance of biosimilars when more than one branded product is available on the market. The ability to share information among national regulators under the Act becomes vital. Australia has a streamline parallel evaluation by TGA and for listing under the PBS.

*This in Australia denotes 'recombinant bacteria E.coli' and indicates production from bacteria genetically modified by recombinant DNA technology Iref: TGA (2013) Australian Public Assessment Report for Filgrastim (rbe), proprietary product name Zarzio, sponsor Sandoz Pty Ltd, Canberra, ACT: Department of Health.

\section{Global information sharing}

The quality of 'follow-on biologics' manufactured in low-income countries may be sufficiently different to those manufactured in more strictly regulated high-income countries that they do not qualify as biosimilars. Nonetheless, the latter countries can learn from the experience of the former, which may have the large population necessary to study the efforts of biological exposures. With the ease of international movement and ability of any citizen to source cheaper 'follow-on biologics' from lowincome countries, pharmacoepidemiological adverse effects data and information on management could be gleaned from information sharing with low-income countries. The sharing of information also enables low-income countries to have access to essential information about a particular biological, and in the process strengthen their own capacity. Australia has established trade relationships and is in close geographical proximity to the Asian biocluster - specifically China, India, Japan and South Korea. Australia has a reputation of producing high quality pharmaceuticals (including biologicals) [7], stable regulatory and remuneration frameworks, and a sound national medicines policy that advocates for a viable pharmaceutical industry and affordable access that have all survived successive changes of government. This puts Australia in a unique position to influence the Asia-Pacific regional regulation of biosimilars.

\section{Post-registration: Pharmaceutical Benefits Scheme (PBS)}

PBS is the monopolistic buyer of pharmaceuticals in Australia. Section 101 of the National Health Act 1953 stipulated that the Pharmaceutical Benefits Advisory Committee can only recommend listing a pharmaceutical on PBS after a positive cost-effectiveness or cost-minimization analysis of the application. If the application is for a product, which is more costly than alternate therapies, significant improvement in the efficacy or reduction of toxicity needs to be demonstrated. This is the legislative basis for reference pricing or benchmarking in Australia. Prices of all pharmaceuticals in the group are tied to that of the lowest, or occasionally the average, price in the group. To further contain costs through increased use of generics, a series of amendments were made to the Act. Of relevance are brand premiums in 1990, brand substitution by pharmacists in 1994 and therapeutic group premiums in 1998 [20, 21]. More recently in 2007, Formula 1 (F1) and Formula 2 (F2) reference pricing was introduced. Pharmaceuticals listed in the F1 schedule are mostly stand-alone branded innovator drug products and not interchangeable. Pharmaceuticals listed on the F2 schedule are 'generic'. When an equivalent generic drug becomes available, the innovator drug can be moved from F1 to F2, resulting in a significant price reduction. Section 99ACEA of the Act clarified that such a price reduction applies to the 'same pharmaceutical item', 'same drug' and 'biosimilar'. The Australian Government can move innovator biological products from F1 to F2 and apply the compulsory price reduction when a biosimilar becomes available on PBS. However, as of October 2014, the biosimilar epoetin lambda was still assigned the higher F1 pricing. Likewise, all somatropins in Australia continued to have F1 pricing as they were approved and registered as new entities.

Other features of the 2007 amendment (F1-F2 pricing) include price disclosure for pharmaceuticals listed in the F2 schedule, termination of reference price link between pharmaceuticals listed in F1 and F2 schedules, and the precondition for pharmaceuticals listed in the F2 schedule to be 'interchangeable on an individual patient basis'.

The issue of interchangeability and substitution was coined the 'fifth hurdle' of regulating biosimilars [22]. In Australia, most - if not all - biosimilars are currently dispensed through hospital pharmacies. Both TGA and PBS do not allow automatic substitution of biosimilars [23] and none of the currently available biosimilars are deemed interchangeable [24]. Australia's lead evidence-based medicine/quality use of medicine agency - NPS MedicineWise - advises clinicians to view switching and substitution as a change in clinical management [24]. This advice is likely to confuse clinicians, as there are a number of pseudobiosimilars, e.g. Aczicrit, Grandicrit and Novicrit all marketed by Sandoz Pty Ltd, on the market. An analysis needs to be conducted to ascertain whether such pseudo-biosimilars have the effect of saturating the market and forcing out competition that would infringe the misuse of power provision under section 46 Competition and Consumer Act 2010.

\section{Conclusion}

Australia is a relatively small market for multinational pharmaceutical manufacturers; however, its reputation of producing high quality pharmaceuticals, close proximity to, and strong trade relationship with, the Asian biocluster puts Australia in a unique position to influence the regional regulation of biosimilars. Three specific aspects of incremental changes to the Australian regulation of biosimilars in relation to potential public cost savings are described here. The Raising the Bar amendments to the Australian patent system may reduce the scope of what an innovator can claim to be patentable, and encourage early entry by biosimilars. The fact that biosimilars still attract F1 pricing may be an economic incentive provided by the PBS until the necessary volume threshold is reached by the biosimilars sponsors. For the policymakers, the affirmation that it is 
lawful for TGA to share commercial confidential information with national and international regulators, and the shorter data exclusivity period, may result in more efficient decision-making in granting biosimilar approval and licensing by TGA

\section{Acknowledgement}

I acknowledge and appreciate the guidance and suggestions from the editors and my hepatitis $\mathrm{C}$ research collaborators, although I accept all responsibility for this work. This work is supported by the Queensland University of Technology's Early Career Academic Recruitment and Development Grant.

\section{Editor's note:}

The Australian Government announced on 24 November 2014 that it would cease joint effort with the current New Zealand Government to establish the proposed joint therapeutic products regulator. However, in the joint media release by both countries' Minister of Health, Australia and New Zealand remain committed to cooperate on the regulation of therapeutic products. Australia's TGA and New Zealand's Medicines and Medical Devices Safety Authority (Medsafe) will continue to explore other means of harmonization activities under the terms of the treaty. These include new information sharing agreement and formalizing mutual recognition of good manufacturing practice audits.

\section{Competing interests: None.}

Provenance and peer review: Not commissioned; externally peer reviewed.

\section{References}

1. Organisation for Economic Co-Operation and Development. What future for health spending? OECD Economics Department Policy Notes, No. 19 June 2013 [homepage on the Internet]. 2013 Jun 25 [cited 2014 Nov 20]. Available from: http://www.oecd.org/eco/growth/aaaaaawhatfuture.pdf

2. Joumard I, André C, Nicq C, Health care systems: efficiency and institutions. 2010, Organisation for Economic Co-operation and Development: Paris [homepage on the Internet] 2010 May 19 [cited 2014 Nov 20]. Available from: http://www.oecd.org/officialdocuments/publicdisplaydocumentpdf/?doclang uage $=$ en $\&$ cote $=\mathrm{eco} / \mathrm{wkp}(2010) 25$

3. Lofgren H. Generic drugs: international trends and policy development in Australia. Pharmaceutical Industry Project: Equity, Sustainability and Industry Development Working Paper Series. August 2002, Centre for Strategic Economic Studies: Melbourne. 2002 Sep 28 [cited 2014 Nov 20]. Available from: http://vises.org.au/documents/pharma/10-Role_of_generics.PDF

4. Haustein R, et al. Saving money in the European healthcare systems with biosimilars. Generics and Biosimilars Initiative Journal (GaBI Journal) 2012;1(3-4):120-6. doi:10.5639/gabij.2012.0103-4.036

5. IMS Health. Shaping the biosimilars opportunity: a global perspective on the evolving biosimilars landscape. 2011 [homepage on the Internet]. 2012 Jan 5 [cited 2014 Nov 20]. Available from: http://www.imshealth.com/ims/Global/ Content/Home\%20Page\%20Content/IMS\%20News/Biosimilars_Whitepaper.pdf

6. Australian Government. Department of Health and Ageing. Strategic review of health and medical research. Final report. February 2013.

7. The Allen Consulting Group. Drivers of pharmaceutical industry investment understanding Australia's competitive position. Final report to Medicines Australia and Research Australia. September 2006 [homepage on the Internet] 2009 Sep 15 [cited 2014 Nov 20]. Available from: http://medicinesaustralia.com. au/files/2010/01/Drivers-of-Pharmaceutical-Industry-Investment-July-20061.pdf
8. Grant K. Ensuring the quality of biosimilars through evaluation and postmarket monitoring. in National Medicines Symposium 2014. Medicine in health: Shaping our future. 2014. Brisbane, QLD: NPS MedicineWise.

9. Australian Department of Innovation, Industry, Science and Research. IP Australia. Pharmaceutical patents review draft report 2013 [homepage on the Internet]. [cited 2014 Nov 20]. Available from: www.ipaustralia.gov.au/ pdfs/Draft_Report_PharmaReview.doc

10. Schellekens H, Jiskoot W. Eprex-associated pure red cell aplasia and leachates. Nat Biotechnol. 2006;24:613-4.

11. Hörl WH. Differentiating factors between erythropoiesis-stimulating agents: an update to selection for anaemia of chronic kidney disease. Drugs. 2013;73(2): 117-30.

12. Australian Department of Innovation, Industry, Science and Research. IP Australia. Pharmaceutical patents review: background and suggested issues paper. 2012 [homepage on the Internet]. [cited 2014 Nov 20]. Available from: http://www.ipaustralia.gov.au/pdfs/Background_and_Suggested_Issues_ Paper_PharmaReview.doc

13. Lexchin J, et al. Pharmaceutical industry sponsorship and research outcome and quality: systematic review. BMJ. 2003;326(7400):1167-70.

14. Kowalchyk K, Crowley-Weber C. Biosimilars: impact of differences with Hatch-Waxman. Pharm Pat Anal. 2013;2(1):29-37.

15. Australian Government. Department of Health. Therapeutic Goods Administration. TGA apporach to disclosure of commercially confidential information (CCI). 7 May 2014 [homepage on the Internet]. 2014 [cited 2014 Nov 20]. Available from: http://www.tga.gov.au/publication/tga-approach-disclosurecommercially-confidential-information-cci

16. Australian Government. Department of Health. Therapeutic Goods Administration. EU DCP: International collaboration for the evaluation of generic drugs. 12 August 2014 [homepage on the Internet]. 2014 [cited 2014 Nov 20]. Available from: https://www.tga.gov.au/media-release/eu-dcp-internationalcollaboration-evaluation-generic-drugs

17. GaBI Online - Generics and Biosimilars Initiative. EMA and FDA extend quality collaboration [www.gabionline.net]. Mol, Belgium: Pro Pharma Communications International; [cited 2014 Nov 20]. Available from: www.gabijournal.net/news/ema-and-fda-extend-quality-collaboration.

18. GaBI Online - Generics and Biosimilars Initiative. Europe-Japan cooperation on generics and biosimilars regulation [www.gabionline.net]. Mol, Belgium: Pro Pharma Communications International; [cited 2014 Nov 20]. Available from: www.gabionline.net/Policies-Legislation/Europe-Japan-cooperation-ongenerics-and-biosimilars-regulation

19. Power DA. Licensing and prescribing biosimilars in Australia. Generics and Biosimilars Initiative Journal (GaBI Journal). 2013;2(3):152-4. doi:10.5639/ gabij.2013.0203.030

20. Hassali A, Stewart K, Kong D. Quality use of generic medicines. Australian Prescriber. 2004;27:80-1.

21. Australian Government. Department of Health. Pharmaceutical Benefits Scheme Therapeutic group premium policy [homepage on the Internet]. 2014 [cited 2014 Nov 20]. Available from: http://www.pbs.gov.au/browse/group-premium

22. Ebbers HC, Chamberlain P. Interchangeability: an insurmountable fifth hurdle? Generics and Biosimilars Initiative Journal (GaBI Journal). 2014;3(2):88-93. doi:10.5639/gabij.2014.0302.022

23. Australian Government. Department of Health. Discussion paper on Similar Biological Medicinal Products (SBMP). 14 July 2010 [homepage on the Internet]. 2014 [cited 2014 Nov 20]. Available from: http://www.tga.gov.au/joint-tgapbddiscussion-paper-similar-biological-medicinal-products-sbmps

24. National Prescribing Services Ltd. Biosimilars - what you need to know. Health News and Evidence. 7 November 2013 [homepage on the Internet]. 2014 [cited 2014 Nov 11]. Available from: http://www.nps.org.au/publications/ health-professional/health-news-evidence/2013/biosimilars\#References.

DOI: 10.5639/gabij.2014.0304.042

Copyright (C 2014 Pro Pharma Communications International 